\title{
SunRise: LARGE SCALE DEMONSTRATOR OF THE SMART WATER SYSTEM
}

\author{
E. FARAH, A. ABDALLAH \& I. SHAHROUR \\ Laboratory of Civil Engineering and geo-Environment (LGCgE) Lille 1 University, France.
}

\begin{abstract}
The development of new monitoring and control technologies has changed the management of water distribution systems (WDSs) from passive to more efficient by generating the notion of a Smart Water Network (SWN). These technologies provide the real-time monitoring of the urban water networks and, consequently, improve the faults diagnosis. This article presents SunRise - Smart Water: a demonstration site of a SWN. The large-scale demonstrator is well equipped by a set of sensors that measure continuously the hydraulic characteristics of the system. The flow readings collected from the sensors are statistically analysed using the k-means algorithm evaluated by the entropy scorer to regroup clusters with same behaviour in terms of water usage. In parallel, the smart monitoring of the water network in the demo site has allowed for leakage detection either by following the water consumption patterns or by computing the minimum night flow (MNF).

Keywords: smart water network, automatic meter readings, monitoring, leakage, minimum night flow.
\end{abstract}

\section{INTRODUCTION}

World population growth, rapid urbanization, climate change, aging infrastructure and weak policies increase the pressure on water resources. According to UN-Water, it is estimated that 1.8 billion people will be living in countries with absolute water scarcity by 2025 , and almost two-thirds of the world population could be under conditions of water stress [1]. Water is delivered from the source to the user through complex distribution systems. These networks have to provide safe and potable water with sufficient pressure. However, a failure in water distribution systems (WDSs) leads to water loss and a degradation of its quality.

Therefore, a new water management strategy is strongly needed to monitor the distribution networks carefully and detect any faults immediately.

The new Information and communication Technologies (ICT) applied in urban networks has generated the notion of a Smart City, where the infrastructure components become more intelligent, interconnected and efficient [2]. The successful results of the smart grid implementation in the electrical field [3] encouraged water utilities to apply the smart approach in the WDSs. The main objective of a smart water network (SWN) is to build a complete monitoring system, integrating sensors technology, data acquisition, data interpretation and decision for real-time management [4]. The process of a SWN consists of five steps [5]. Before applying the smart concept, it is important to have a full knowledge and a schematic visualization of the network. All the characteristics of the physical components of a WDS such as pipes, valves, reservoirs, pumps, air valves and stabilizers are collected and then regrouped in a Geographic Information System (GIS). The next step consists of setting up a set of sensors that measure continuously the water parameters such as flow, pressure and quality. The data collected from the sensors are then transferred through communication channels 
to an information system. The database platform obtained is then used to organize the measured data, present it through the GIS model and set up a customer information system. In parallel, the water utilities rely on different methods to detect in real-time any anomalies. For example, in order to suspect leaks in a water network, the supply operators use a common method based on the Minimum Night Flow (MNF). The MNF is measured usually between 2 a.m .and 4 a.m. when customer demand is least and leakage is dominant in a District Metered Area (DMA) [6]. A DMA is created by subdividing the water distribution network into discrete zones by the permanent closure of valves, in which the volume of water entering and leaving the zone is metered [7]. A leak alarm is generated when the MNF extracted in the DMA exceeds a threshold set by water utility companies taking into consideration that the MNF depends on the age and the length of the pipes, the number of connections and the pressure [8].

\section{SITE DESCRIPTION}

The scientific campus of Lille 1 University was inaugurated in 1967. It is located in Villeneuve d'Ascq in the suburbs of Lille, North of France, and covers an area of $1.1 \mathrm{~km}^{2}$. The campus is representative of a small city of around 25,000 users including 4,000 inhabitants living in university residences. The campus comprises 145 buildings that are 5 to 50 years old spread over a total construction area of $325,000 \mathrm{~m}^{2}$. These buildings are used for teaching, research, administration, services, student residences, restaurants and entertainment activities. The campus also includes $100 \mathrm{~km}$ of urban networks such as drinking water, sewage, electrical grid and district heating.

The water network system on the Lille Campus dates from 1964. It was established during the construction stages of the site. It includes $15 \mathrm{~km}$ of grey cast iron pipes with a diameter varying from 20 to $300 \mathrm{~mm}$. It also consists of 49 hydrants designed according to fire fighting standards, 250 isolation valves and a set of stabilizers and air valves. Figure 1 illustrates a GIS map of the water network of the campus describing the hydraulic components of the system as well as the instrumentations.

\section{INSTRUMENTATIONS}

\subsection{Automatic meter readings}

The water distribution network is also equipped with 93 Automatic Meters Readings (AMRs) that measure the water consumption hourly and detect abnormal consumption related to leakage or abnormal use. The AMR consists of two parts: meter reading devices and base stations. Each meter located in the buildings has an impulse sensor and a VHF radio transmitter. The index of the water consumption is read by the impulse sensor that converts it to an electronic index. The impulse counter is connected to a microcontroller unit to store the cumulative readings for transmission. The readings are transmitted via a radio frequency of $169 \mathrm{MHz}$ to the base stations. The radio receivers are installed on the roofs of buildings and gather all indexes transmitted within a maximum range of 300 meters for urban area. The base statins then send the collected data through the mobile network to a central information system with four signals per day in 1/10th of a second. The telemetry principle for the AMRs installed in the campus is described in Figure 2.

Figure 3 shown below describes an example of measurements collected from a principal meter measuring the water consumption of a sector. 


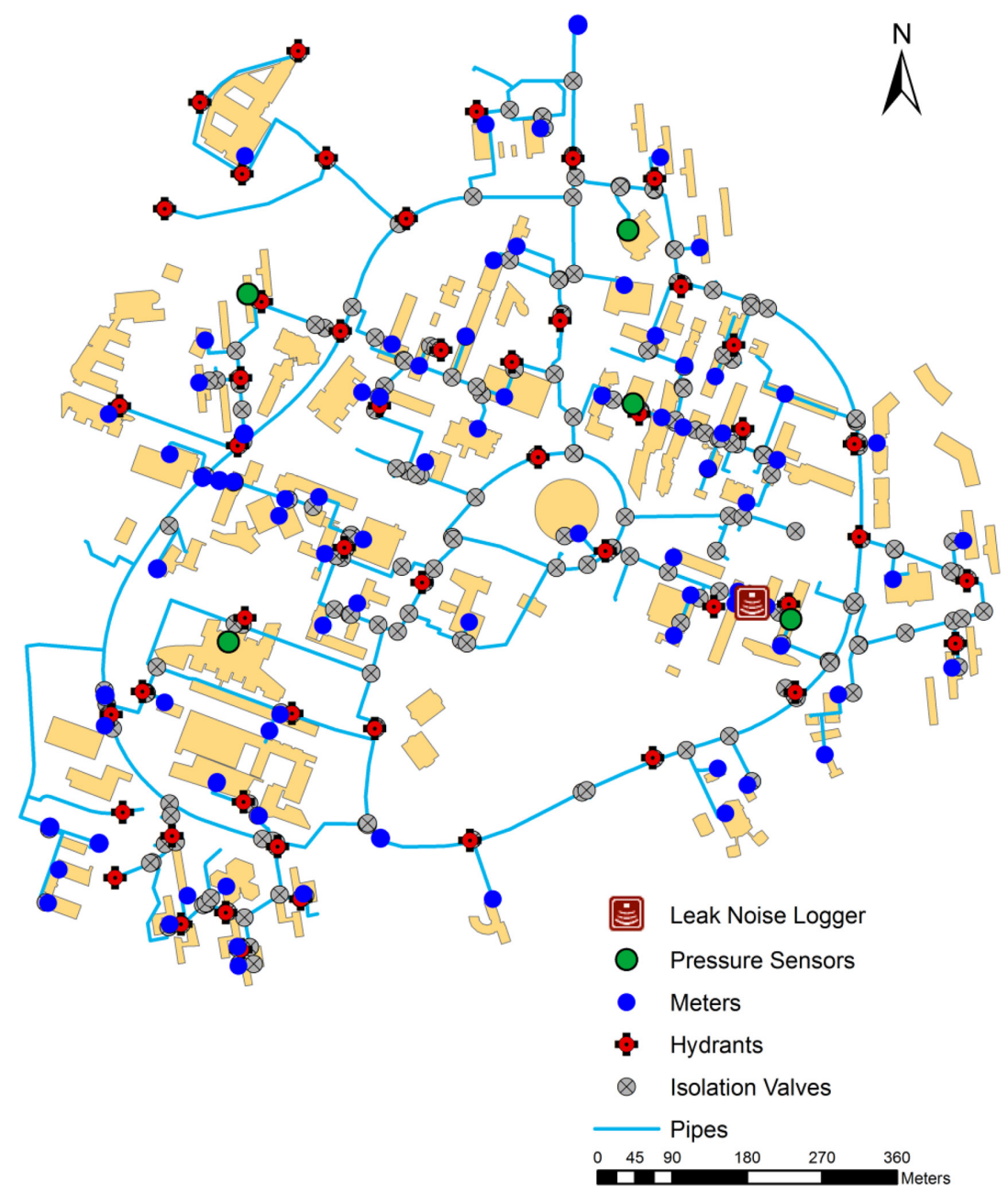

Figure 1: GIS map for the water distribution network of the campus.

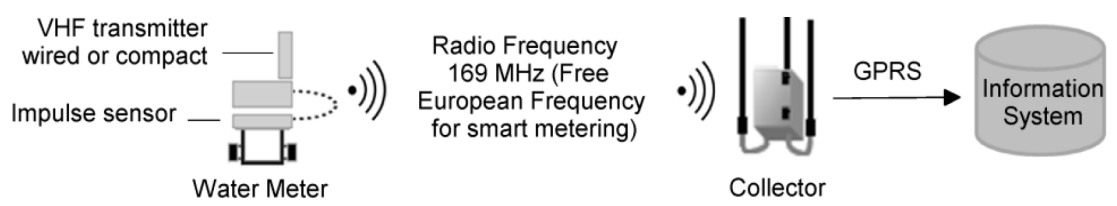

Figure 2: Telemetry architecture to remote water meter readings.

\subsection{Pressure sensors}

A set of five piezoresistive pressure sensors is installed in the campus covering the majority of the zones. Each sensor measures the pressure in hydraulic pipes. It is connected to a 


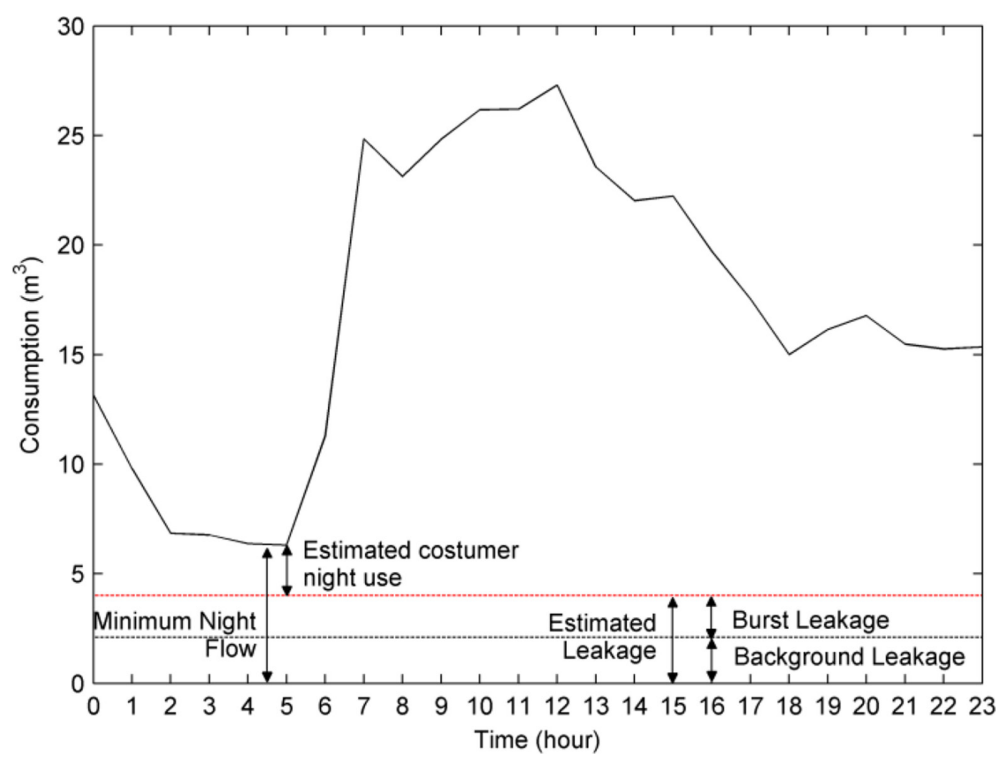

Figure 3: Typical 24-hour profile for a principal meter.

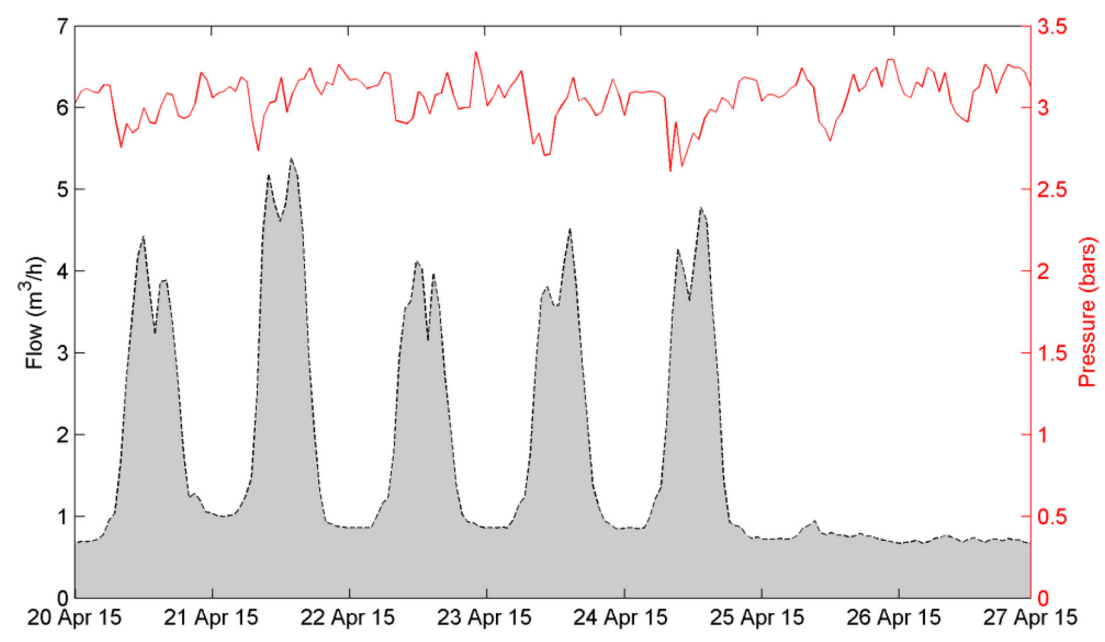

Figure 4: Flow and pressure profile for the chemistry sector during a week.

standard thread and delivers a signal proportional to the pressure in the pipe. The sensor is attached to a data logger used to remote the pressure values measured each 15 minutes. Based on a high-performance internal antenna, the data loggers send their gathered data via SMS at user-definable periods (every 8 hours in our case).

Figure 4 shows the weekly pressure and flow profile for the chemistry sector between 20th and 27th April 2015. The profile consumption describes the activity of the chemistry buildings during business days and weekends. An MNF of $0.8 \mathrm{~m}^{3} / \mathrm{h}$ remains stable in the weekend. This can be explained either by the non-stop activity of the machines in these buildings or 
probably by a background leakage. The pressure values measured in this zone show a pressure drop for a sudden increase of the flow. The average pressure in the chemistry sector is about 3.1 bars.

\subsection{Noise logger - EAR system}

EAR (Early Alarm Recording) is a listening system that enables a permanent and reliable monitoring system to increase the water network performance. The system is composed of: (i) hydrophone positioned into the fluid vein that allows direct acquisition of noises carried out by the water and (ii) SEBA LOG HYDRO transmitter that enables the transmission of the data recorded. The EAR system is installed on a $100 \mathrm{~mm}$ grey cast iron pipe that passes in a technical gallery and supplies the buildings in the Biology sector of the campus. The system is programmed to automatically turn on at night between $2 \mathrm{a} . \mathrm{m}$. and $4 \mathrm{a} . \mathrm{m}$. to monitor system noise and transform the acoustic vibrations caused by pipe leaks into actionable information on the location of leaks. These units collect noise data during the night in order to minimize the interference from other noise sources, such as roads traffic or high daytime water consumption sound. Figure 5 shows a measurement example of noise level and frequency on 23rd December 2015. The minimum noise level reported during early morning is $36 \mathrm{~dB}$ at $30 \mathrm{~Hz}$.

\section{WATER CONSUMPTION ANALYSIS}

The data are collected from 93 water meters. Each smart meter generated information every hour, and there are 4 years of data available from 2012 to 2015. All data are available in PostgreSQL tables. The water data table is composed of 3 elements: time-stamp, meter IDs and the consumption value. Among the 93 AMRs, there are 13 general meters that measure the volume of water entering the campus and 70 meters recording on an hourly basis the water used inside the buildings of the university. The water consumption distribution shows that, in 2015 , the student residences $\left(119,080 \mathrm{~m}^{3}\right)$, the chemistry sector $\left(15,370 \mathrm{~m}^{3}\right)$, the physics sector $\left(13,350 \mathrm{~m}^{3}\right)$ and the biology sector $\left(9,460 \mathrm{~m}^{3}\right)$ are the sectors that consume most water and account for almost $80 \%$ of the total water consumption of the campus. The

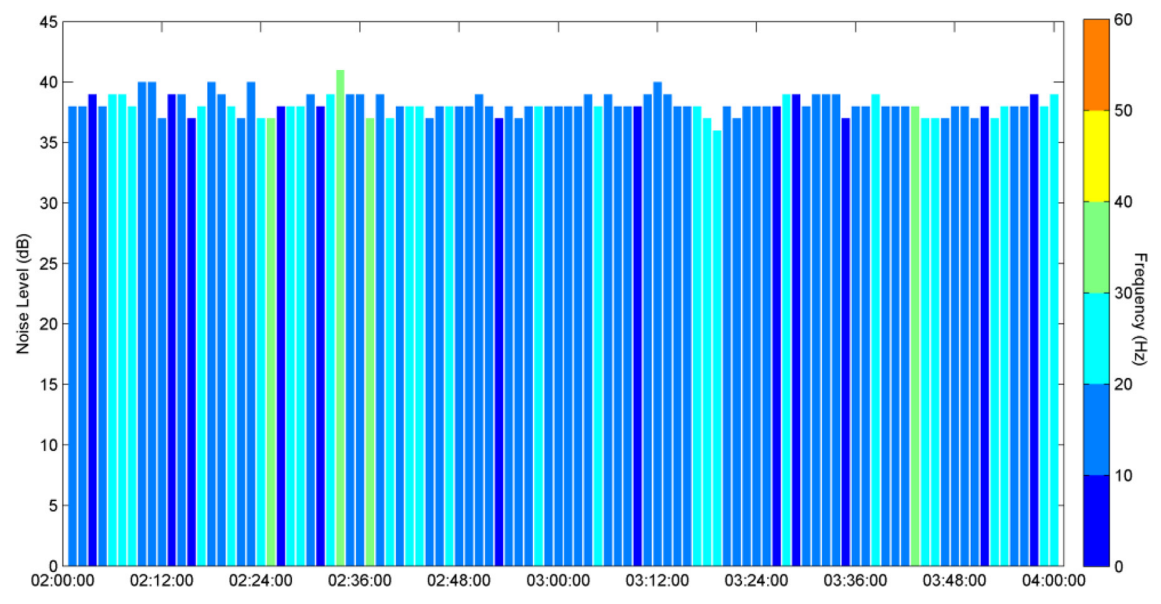

Figure 5: Noise level and frequency measured by EAR system on 23/12/2015. 


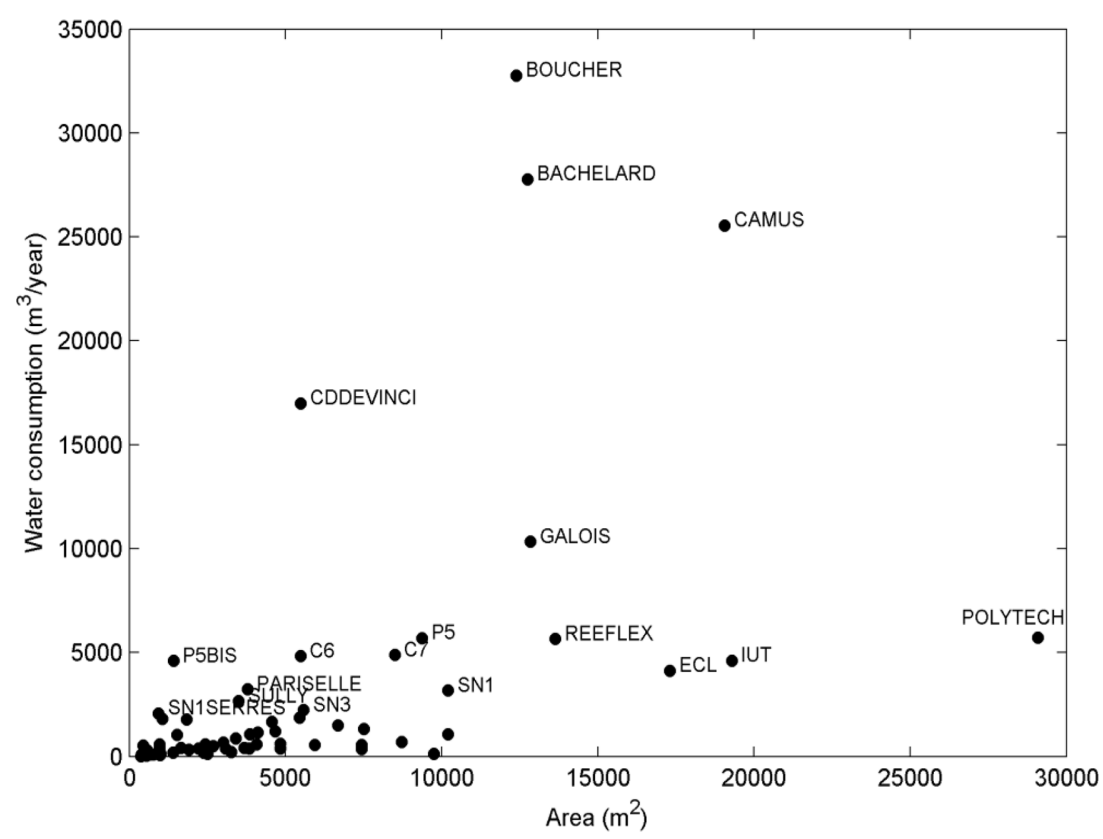

Figure 6: Water consumption of the campus' building according to the corresponding areas.

analysis of the water consumption at the level of sub-metering has been performed to highlight the activities that represent the high consumption. Figure 6 shows the water consumption in 2015 of the buildings according to the corresponding areas.

As shown in Figure 6, the students' residences (BOUCHER, BACHELARD, CAMUS, L.DEVINCI) consume the largest volume. The 4,000 students living in the campus use water for drinking, cooking, washing, cleaning, toilets etc. The C6 and C7 buildings from the chemistry sector, the SN1 and SN1Serres from the biology sector and the P5 building from the physic sector consume a significant volume of drinking water. These buildings contain many machines that use water in large quantities and remain turned on even at night and sometimes during the weekend.

From the above diagram, it is noted that the engineering school Polytech is distinguished from other buildings because of its low water consumption taking into account its wide area. It is also remarkable that the classification of the water consumption of the building according to the areas present some limitations. For example, the two student residences (GALOIS and REEFLEX) are not regrouped based on their usage category. Moreover, the university restaurants (PARISELLE, SULLY) are grouped with the teaching and administrative buildings. Therefore, the water consumptions have to be clustered according to the type of usage of the buildings in the demo site.

\subsection{Clustering}

In order to group buildings based on the same parameters, the k-Means algorithm was used. Since the k-Means algorithm is a distance-based method (Euclidean distance), all input features are normalized into the $[0,1]$ interval to get comparable ranges. The algorithm starts 
with initial seeds of clustering. The data are then compared with each seed by means of the Euclidean distance and are assigned to the closet cluster seed. The method is then repeated again and again until the convergence. The most important challenge for k-Means is that the number of clusters has to be specified first. Kaufman and Rousseeuw [9] proposed the Silhoutte plot method. The Silhouette analysis provides a succinct representation of how close each point in one cluster is with points in the neighbouring clusters. Kailing and Kriegel [10] suggested measuring the quality to evaluate the clustering outcome and compare it with the reference clustering:

$$
Q_{k}(C)=\sum_{C_{i} \in C} \frac{\left|C_{i}\right|}{|O|} \cdot\left(1-\text { entropy }_{k}\left(C_{i}\right)\right)
$$

where $\mathrm{O}$ represents the set of data objects, $\mathrm{k}$ is the reference clustering of $\mathrm{O}, \mathrm{C}$ is the clustering to evaluate, and entropy $\mathrm{k}_{\mathrm{k}}\left(\mathrm{C}_{\mathrm{i}}\right)$ the entropy of cluster $\mathrm{C}_{\mathrm{i}}$ with respect to $\mathrm{k}$. The quality score can be equal to 1 if the clustering results match the reference clustering, or 0 if all clusters are completely mixed or all points are predicted to be noise [11].

The percentage measures from early morning until late night as well as the hourly consumption, the average water usage by business days and holidays and the overall consumption were used to group the meter IDs related to the university buildings into 12 clusters that behave similarly in terms of water usage. The reference clusters refers to the usage of the university buildings in the campus classified into 8 categories: administration, teaching, research, teaching and research, catering, student residences, sport and services. The quality score for 12 clusters is 0.52 showing that a reasonable structure has been found.

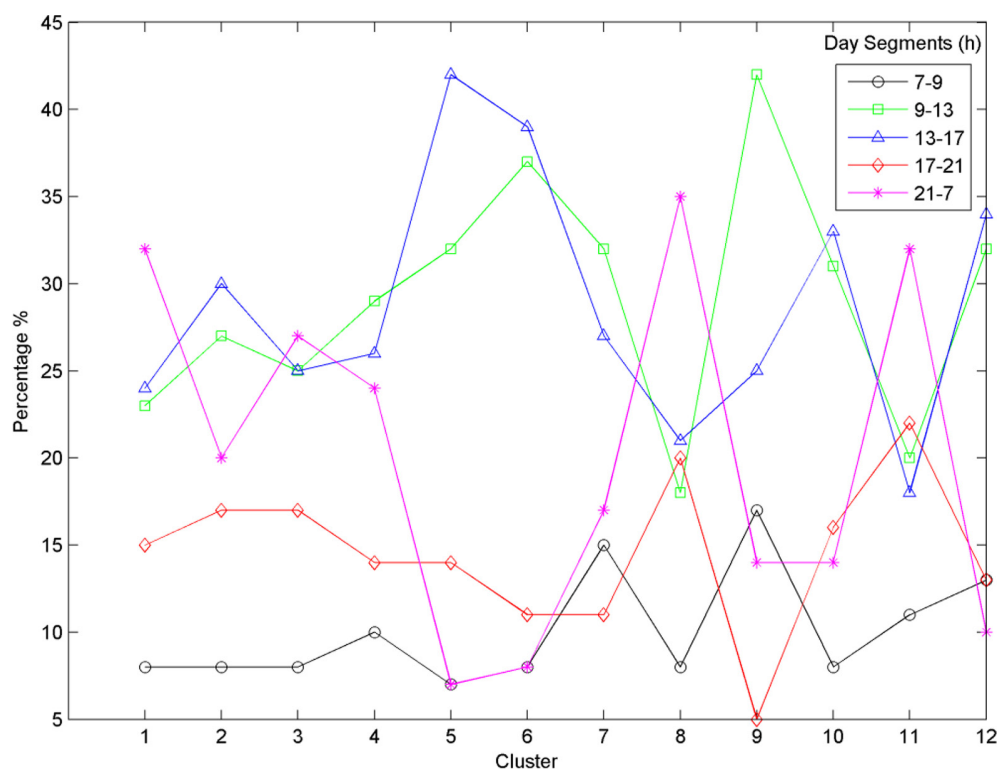

Figure 7: Percentage of water usage per day segment for each cluster. 
According to Figure 7, some clusters can be regrouped together to form 4 main categories:

1. Morning usage for clusters 7 and 9 . The first group contains meter ID with a high morning usage of water especially between 7 a.m. and 9 a.m. These two clusters contain certainly the restaurants of the campus, which are highly active in the morning and during midday.

2. Morning and afternoon usage for clusters 2, 5, 6, 10 and 12. The second group represents the meter ID related to the buildings for teaching, administration and services, which consume water mainly during the working hours between 9 a.m. and 5 p.m.

3. Night usage for clusters 1,8 and 11 . These clusters represent definitely the student residences and the buildings for sport and research, which are highly active during the night.

4. Day and night usage for clusters 3 and 4 . The last collection is made of clusters with a more equally distributed usage of water from 9 a.m. till 7 a.m. on the next day. These clusters represent mainly the buildings for teaching as well as for research regarding the late evening and early morning water usage. It may comprise the biology and chemistry research buildings, which contain some machines that need water and stay turned on even in the night.

\section{LEAK DETECTION}

The smart monitoring of the water consumption in the distribution networks using the AMRs allows detecting the leaks in quasi real-time. The water loss is detected inside the buildings by monitoring the water consumed over the day. Using the readings from the AMRs installed in the buildings in the demo site, a leak has been detected in a building in the Physics sector. As shown in Figure 8, comparing the flow rate over the 4 weeks of May 2014, a leak alarm is generated during the weekend of the 2 nd week of the mentioned month.

The MNF approach is also applied as a leak detection method in the demo site. In order to avoid the false values due to a dysfunction of the sensor, the night flow is computed as the percentile at $5 \%$ of the measured values over the restricted time series between 2 a.m. and

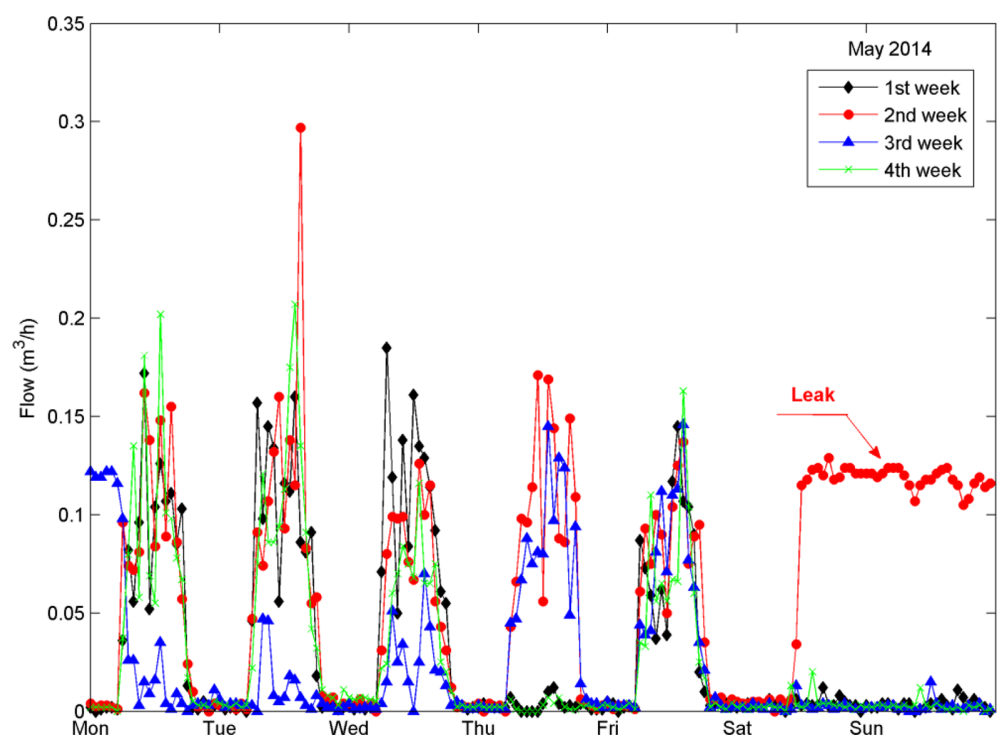

Figure 8: Water consumption in a building in the Physics sector over the 4 weeks of May 2014. 


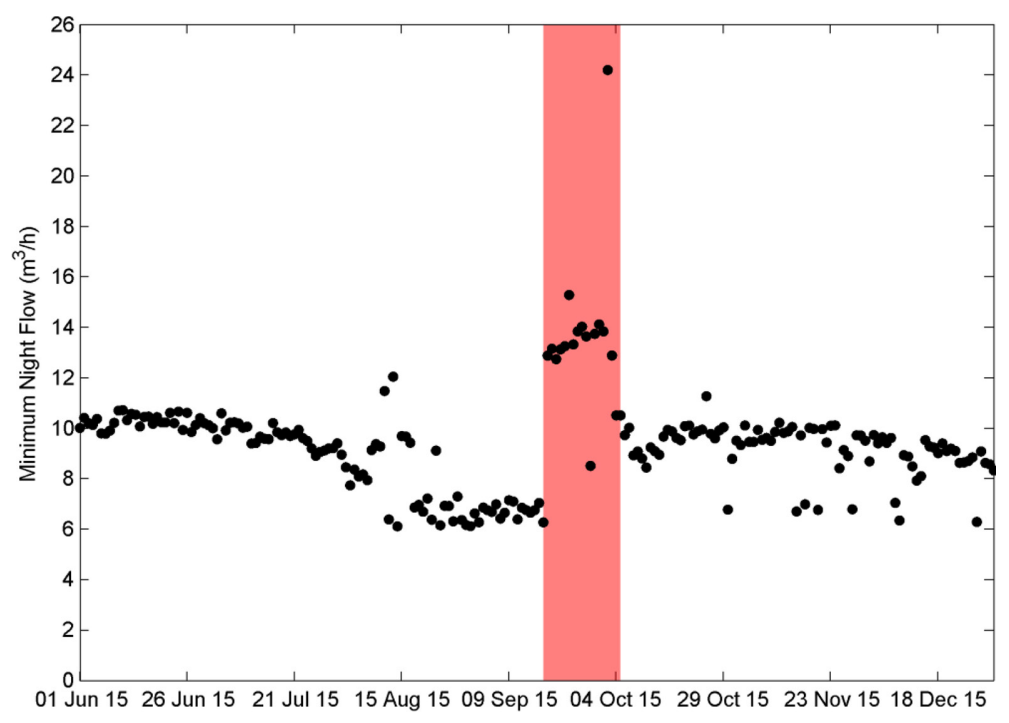

Figure 9: The MNF computed in a sector.

4 a.m. It finds a value that is above $5 \%$ of the points and below $95 \%$ of the remaining points instead of taking the exact minimum value over the defined time series.

This approach was able to detect a leak in a sector of the campus that includes engineering schools, students' residence and a university restaurant. The computed MNF from the values measured by a principal meter installed at the entry of this sector is shown in Figure 9. The leak alarm is generated on the 17th of September 2015 when the MNF exceeds the historical recorded one. The non-reported leak was localized by surveying the suspicious area using the ground microphones. Noting that, according to Figure 9, the decrease of the MNF values between July and August 2015 is explained by the non-occupancy of the university buildings of this sector during the summer holidays.

\section{CONCLUSION}

Many common challenges with regard to water utilities, including leak detection and customer service can be improved by integrating a SWN. This article has presented a large-scale demonstrator of a smart water system: SunRise - Smart Water. All the physical components of the network and the hydraulic sensors are well defined in a GIS. The water consumption values collected via the telemetry system in the demo site has been used to regroup buildings according to water usage. The k-means algorithm has been applied to cluster together the AMRs based on similar behaviours and categorize, without any prior knowledge, the type of usage of the building depending on the water consumption. The water loss in the demo site has been detected either by monitoring the flow rate inside a building or by computing the MNF for a sector.

\section{REFERENCES}

[1] SENSUS, Water 20/20 - Bringing Smart Water Networks Into Focus, 2012.

[2] Chourabi, H., Nam, T., Walker, S. \& Gil-Garcia, J.R., Understanding smart cities: an integrative framework. in 45th Hawaii International Conference on System Science, 2012. 
[3] Fang, X., Misra, S., Xue,G. \& Yang, D., Smart grid-the new and improved power grid: a survey. Communications Surveys \& Tutorials, IEEE, 14(4), pp. 944-980, 2012. http://dx.doi.org/10.1109/SURV.2011.101911.00087

[4] Boulos, P.F. \& Wiley, A.N., Can we make water systems smarter? Opflow, 39(3), pp. 20-22, 2013. http://dx.doi.org/10.5991/OPF.2013.39.0015

[5] Cahn, A., Shaping the architecture of smart water networks, in water \& sewerage journal, 3, pp. 13-15, 2013.

[6] Thornton, J., Sturm, R. \& Kunkel, G., Water loss control. 2008: McGraw Hill Professional, 2nd edn., 632

[7] Morrison, J., Managing leakage by district metered access: a practical approach. Water, 21, pp. 44-46, 2010.

[8] Alkasseh, J.A., Adlan, M.N., Abustan, I., Aziz, H.A. \& Mohamad Hanif, A.B., Applying minimum night flow to estimate water loss using statistical modeling: a case study in Kinta Valley, Malaysia. Water Resources Management, 27(5), pp. 1439-1455, 2013. http://dx.doi.org/10.1007/s11269-012-0247-2

[9] Kaufman, L. \& Rousseeuw, P.J., Finding groups in data: an introduction to cluster analysis, John Wiley \& Sons, 344, 2009.

[10] Kailing, K., Kriegel, H.P., Pryakhin, A. \& Schubert, M., Clustering multi-represented objects with noise. In Advances in Knowledge Discovery and Data Mining, Springer, pp. 394-403, 2004. http://dx.doi.org/10.1007/978-3-540-24775-3_48

[11] Ay, M. \& Kisi, O., Modelling of chemical oxygen demand by using ANNs, ANFIS and k-means clustering techniques. Journal of Hydrology, 511, pp. 279-289, 2014. http://dx.doi.org/10.1016/j.jhydrol.2014.01.054 